\title{
ESTABILIDADE E ADAPTABILIDADE DE LINHAGENS E CULTIVARES DE FEIJÃO DO GRUPO CARIOCA
}

\section{STABILITY AND ADAPTABILITY OF CARIOCA BEAN LINES AND CULTIVARS}

\author{
Haroldo Tavares ELIAS ${ }^{1}$ \\ Rogério Luiz BACKES² \\ Maria Celeste Gonçalves VIDIGAL ${ }^{3}$ \\ Alvadi Antonio BALBINOT JR. ${ }^{4}$ \\ Silmar HEMP ${ }^{5}$
}

\begin{abstract}
RESUMO
O feijão é cultivado sob diferentes condições de ambientes e níveis tecnológicos. Estas diferenças aliadas às diferenças entre genótipos e à interação entre genótipos e ambientes são as principais responsáveis pelas variações nas produtividades. A interação genótipo por ambientes tem sido um desfio para a indicação de cultivares e para a seleção de linhagens nos programas de melhoramento. $\mathrm{O}$ objetivo deste trabalho foi avaliar a estabilidade e a adaptabilidade da produtividade de grãos de 14 genótipos de feijão carioca, avaliados em dez ensaios de Valor de Cultivo e Uso (VCU), conduzidos nos anos agrícolas 2000/01 e 2001/02. O delineamento utilizado foi de blocos casualizados, com quatro repetições. A estabilidade e a adaptabilidade foi avaliada por uma metodologia não paramétrica, e metodologias baseadas em regressão linear bissegmentada e linear simples. Os resultados demonstraram que houve concordância entre metodologias na indicação de genótipos, a exceção da recomendação para ambientes desfavoráveis. O genótipo ideal, considerando os parâmetros da regressão bissegmentada para ambientes favoráveis não foi encontrado. Entre os genótipos avaliados destacaram-se especialmente as linhagens Vi 4899, Vi 0699 e Vi 4599, apresentando, de forma geral, melhor produtividade, adaptabilidade e previsibilidade. As linhagens Vi 4899, Vi 0699 e Vi 4599 apresentaram adaptabilidade à ambientes gerais e também foram indicadas junto com LP 97-28 para ambientes desfavoráveis. Em ambientes favoráveis, Vi 4899, FT 97-155 e FTS Magnífico apresentaram as melhores performances.
\end{abstract}

Palavras-Chave: Phaseolus vulgaris; previsibilidade de comportamento; produtividade.

\begin{abstract}
The common bean has been cultivated under different environmental conditions and technology levels. These environmental variations, linked to genotypes differences and interaction between genotypes and environments are the main reasons for those yield variations. The interaction genotype by environments has been a challenge for indication of cultivars and to select lines in breeding programs as well. The objective of this work was to evaluate the stability and adaptability of grain yield in 14 genotypes of carioca bean, studied in ten experiments of Cultivate Value and Using, carried out during agricultural years of 2000/01 and 2001/02. The experimental design utilized was the randomized blocks with four repetitions. The stability and adaptability were evaluated by nonparametric, bi-segmented and simple linear regression methodologies. The results demonstrated a concordance among methodologies for genotypes indications with exception for recommendation in unfavorable environments. The ideal genotype was not found by bisegmented linear regression. The lines Vi 4899, Vi 0699 and Vi 4599 showed adaptability to general environments, and with LP 9728 were indicated to unfavorable environments. In favorable environments Vi 4899, FT 97-155 and FTS Magnífico showed the better performances.
\end{abstract}

Key-words: Phaseolus vulgaris L.; predictability of behavior; yield.

\footnotetext{
${ }^{1}$ Eng. Agr., Doutor, Pesquisador da Epagri/Centro de Pesquisa para Agricultura Familiar. C.P. 791, CEP 89.801-970, Chapecó-SC. Autor para correspondência: htelias@epagri.sc.gov.br.

${ }^{2}$ Eng. Agr., Doutor, Pesquisador da Epagri, Estação Experimental de Canoinhas. E-mail: backes@epagri.sc.gov.br.

${ }^{3}$ Eng. Agr., Doutor, Bolsista Produtividade CNPq, Departamento de Agronomia, Universidade Estadual de Maringá. E-mail: mcgvidigal@uem.br ${ }^{4}$ Eng. Agr., Doutorando do Programa de Pós-Graduação em Agronomia/Produção Vegetal da UFPR; Pesquisador da Epagri/Estação Experimental de Canoinhas. E-mail: balbinot@epagri.sc.gov.br.

${ }^{5}$ Eng. Agr., Mestre, Pesquisador da Epagri/Cepaf. E-mail: hemp@epagri.sc.gov.br.
} 


\section{INTRODUÇÃO}

No início da década de 90 , a cultura do feijão ocupava aproximadamente 300 mil ha no Estado de Santa Catarina, já no ano de 2006, a área cultivada foi de apenas 125 mil ha (SILVA, 2006). Uma das causas da redução de área é a falta de cultivares bem adaptadas, de alta qualidade de grãos e que sejam habilitadas para efeito de seguro agrícola via zoneamento agrícola. Estas são exigências para garantir a competitividade de Santa Catarina na produção de feijão. Destaca-se que para a safra 2006/ 07 haviam apenas sete cultivares de feijão do grupo carioca habilitados para Santa Catarina, portanto aceitos pelo Proagro.

Aproximadamente sessenta mil agricultores cultivam feijão em caráter comercial, e um grande número em caráter de subsistência, o que demonstra a grande importância econômica e social desta cultura em Santa Catarina. Neste contexto, a pesquisa agropecuária poderá contribuir com esta atividade desenvolvendo e identificando novas cultivares mais adaptadas as condições de cultivo do Estado.

O feijão é cultivado em praticamente todo o Estado, sob diferentes condições edafoclimáticas e níveis tecnológicos, sendo a semeadura realizada em duas épocas, a primeira (safra) entre os meses de agosto e outubro e, a segunda (safrinha), primordialmente entre os meses de janeiro e fevereiro (THOMÉ et al., 1997). As diferentes condições edafoclimáticas e a interação genótipo $x$ ambiente $(G \times A)$ têm resultado em grandes variações de produtividade no estado (ELIAS et al., 1999; NUNES et al., 1999; ELIAS et al., 2005).

A interação $G \times A$ é um desafio tanto para indicação de cultivares, quanto para os programas de melhoramento genético, pois resulta em estimativas viesadas dos parâmetros genéticos, e sendo a seleção realizada com base em médias de vários ambientes, não se tem certeza da seleção indicar os genótipos superiores em cada ambiente. Neste sentido, há duas estratégias básicas para reduzir os efeitos da interação $\mathrm{G} \times \mathrm{A}: 1$ ) identificação de cultivares específicos para cada ambiente, o que geralmente é inviável devido ao custo; e 2) obtenção de genótipos com baixa interação $G \times A$. $A$ estratificação do ambiente em sub-regiões mais homogêneas facilita a seleção de genótipos mais estáveis, mas a interação pode continuar significativa devido ao efeito de ano (EBERHART e RUSSELL, 1966; SCAPIN et al., 2000). Assim, mesmo após a estratificação dos ambientes, há necessidade de identificar cultivares de alta estabilidade ou previsibilidade fenotípica.

$\mathrm{Na}$ prática, a busca de cultivares de alta previsibilidade e adaptabilidade tem sido a alternativa mais utilizada (COIMBRA et al., 1999; CARBONELL et al., 2004; ELIAS et al., 2005; OLIVEIRA et al., 2006). Para tanto, são empregadas distintas metodologias que visam fornecer parâmetros para a caracterização da performance genotípica frente as variações ambientais (RAMALHO et al., 1993; CRUZ e REGAZZI, 1997). O termo performance genotípica se refere ao desempenho, comportamento e flutuações de um genótipo quando cultivado em vários ambientes (CRUZ e CARNEIRO, 2003).

Há diferentes conceitos relacionados a adaptabilidade e estabilidade. A adaptabilidade se refere à capacidade do genótipo em responder vantajosamente à melhoria do ambiente, e a estabilidade de comportamento, é a capacidade dos genótipos apresentarem comportamento previsível em função das variações ambientais (LIN et al., 1986; CRUZ e CARNEIRO, 2003). As metodologias para estudo da adaptabilidade e estabilidade diferem quanto aos conceitos associados aos parâmetros estimados, procedimentos biométricos adotados, exigências para utilização e quanto ao número de parâmetros a serem interpretados. De forma que todas as metodologias apresentam vantagens e limitações (VENCOVSKY e BARRIGA, 1992).

No trabalho de avaliação da estabilidade e adaptabilidade realizado por NUNES et al. (1999) em Santa Catarina, não foram identificados e recomendados genótipos do grupo carioca. Mais recentemente, ELIAS et al. (2005) avaliando 24 genótipos do grupo preto e carioca, identificaram a linhagem $\mathrm{CH}$ 90-1535, que posteriormente foi lançada como cultivar sob a denominação de SCS 202 Guará. Portanto, até o momento, SCS 202 Guará é o único genótipo do grupo carioca que mostrou adaptabilidade e estabilidade em Santa Catarina. COIMBRA et al. (1999) também identificaram linhagens do grupo carioca com adaptabilidade e estabilidade específica para a região de Chapecó/ SC.

O objetivo deste trabalho foi avaliar a estabilidade e a adaptabilidade quanto à produtividade de grãos de 14 genótipos de feijão do grupo comercial carioca, cultivados em dez ambientes no Estado de Santa Catarina entre os anos de 2000 e 2002 por meio de três metodologias e discutir comparativamente os resultados.

\section{METODOLOGIA}

Os dados para a análise da performance genotípica deste trabalho são oriundos de ensaios de Valor de Cultivo e Uso (VCU) conduzidos em diferentes regiões do Estado de Santa Catarina nos anos agrícolas 2000/01 e 2001/02 pela Epagri/ Programa de Melhoramento Genético de Feijão. Os experimentos foram conduzidos no delineamento experimental de blocos casualizados, com quatro repetições. A unidade experimental foi constituída por quatro fileiras de quatro metros de comprimento, sendo, para efeito de avaliação, as duas linhas externas de cada parcela consideradas como bordadura.

Os dez ensaios considerados neste trabalho foram conduzidos em diferentes épocas e locais. No ano agrícola 2000/01 foram conduzidos ensaios na primeira época nos seguintes municípios e datas de plantio: Chapecó (28 de setembro), Canoinhas (16 de novembro) e Campos Novos (22 de novembro) e, na segunda época em São Carlos (18 de janeiro), Chapecó (19 de janeiro) e Ituporanga (23 de fevereiro). No ano 2001/02 conduziu-se mais dois ensaios na primeira época, Chapecó (21 de setembro) e Campos Novos (01 de novembro) e, dois na segunda época, Urussanga (06 de fevereiro) e Ituporanga (18 de fevereiro). As adubações de base e cobertura foram realizadas de acordo com a análise de solo. O controle de 
pragas foi realizado conforme a necessidade. Não se efetuou controle químico de doenças da parte aérea. A produtividade de grãos foi avaliada por ocasião da maturação e transformada em kg ha-1 e corrigida para $13 \%$ de umidade.

Avaliou-se a performance de 14 genótipos de feijão do grupo carioca, sendo cinco cultivares (SCS Guará, FTS Magnífico, TPS Bonito, Pérola e Carioca) e nove linhagens desenvolvidas por diferentes instituições de pesquisa $(\mathrm{Cl}$ 9633, Vi 0699, Vi 4599, Vi 4899, LH 11, LP 97-28, LP 97-58, LP 96153 e FT 97-155).

Realizou-se a análise de variância individual dos ensaios, sendo detectada homogeneidade entre os resíduos, pois a relação foi inferior a sete e o número de repetições dos experimentos foi constante, o que, segundo PIMENTEL-GOMES (2000), garante a viabilidade da análise conjunta. $\mathrm{Na}$ análise conjunta, consideraram-se os efeitos de genótipos como fixos e os demais efeitos, como aleatórios. Os ambientes foram classificados em favoráveis ou desfavoráveis de acordo com os índices ambientais, estimados pela diferença entre a média de cada local em relação á média geral, de forma que, índices positivos indicam ambientes favoráveis e negativos indicam ambientes desfavoráveis.

A performance dos genótipos foi avaliada pelas metodologias propostas por: ANNICCHIARICO (1992), CRUZ et al. (1989) e EBERHART e RUSSELL (1966). A metodologia proposta por EBERHART e RUSSEL (1966) é baseada na regressão. Por esta metodologia, os genótipos com ? ${ }_{1 i}$ igual a 1, maior que 1 e menor que 1 , foram classificados como de adaptabilidade geral, adaptabilidade específica a ambientes favoráveis e adaptabilidade específica a ambientes desfavoráveis, respectivamente. Genótipos com ? ${ }^{2} i$ igual a zero são estáveis ou de alta previsibilidade, enquanto genótipos com desvio maior que zero pelo teste $t$, são considerados de estabilidade ou previsibilidade baixa. Adicionalmente, recomendou-se genótipos que apesar da significância do desvio da regressão apresentam $\mathrm{R}^{2}$ acima de $80 \%$ (CRUZ e REGAZZI, 1997).

A metodologia de CRUZ et al. (1989) é baseada em regressão bissegmentada. O genótipo ideal com adaptabilidade geral a ser identificado deve apresentar média alta, ? $\hat{l i}_{l} l$ (baixa resposta a ambiente desfavoráveis), ${ }_{1 i}$ ? $\hat{?}_{2 i}$ ? 1 (alta resposta a ambiente favoráveis). Quanto a estabilidade é desejável, ? $?_{i}^{2}$ ? 0 (desvio da regressão nulo) e adicionalmente, $\mathrm{R}^{2}$ alto. Considerou-se ainda, de boa previsibilidade, genótipos cujo coeficiente de determinação da regressão está acima de $80 \%$.

Para as duas metodologias baseadas na regressão, as hipóteses sobre os coeficientes de regressão foram avaliadas pelo teste $t \mathrm{e}$, as hipóteses sobre a significância dos desvios da regressão foram avaliadas pelo teste $F$, ambos a 5 e $1 \%$ de probabilidade do erro.

ANNICCHIARICO (1992) propôs um índice de confiança de um genótipo apresentar comportamento relativamente superior a média de cada ambiente. Este índice foi obtido a partir da média percentual e do desvio-padrão, de modo que, expressa simultaneamente a adaptabilidade e a estabilidade. $O$ índice é estimado para ambientes geral, favoráveis e desfavoráveis, considerando o comportamento de cada genótipo em todos ambientes, ambientes favoráveis e ambientes desfavoráveis, respectivamente.

As análises estatísticas e biométricas dos dados foram realizadas com auxílio do programa Genes (CRUZ, 2001).

\section{RESULTADOS E DISCUSSÃO}

$\mathrm{Na}$ análise de variância conjunta dos dez ambientes foi detectada interação significativa entre genótipos e ambientes, ao nível de $1 \%$ de probabilidade, pelo teste $F$. Portanto há comportamento diferencial de genótipos entre ambientes, justificando o estudo da estabilidade e adaptabilidade dos genótipos. A produtividade média dos 14 genótipos, considerando todos os ambientes, foi de $1906 \mathrm{~kg} \mathrm{ha}^{-1} \mathrm{e}$, o coeficiente de variação da análise conjunta foi de $16,03 \%$ (Tabela 1). Sete genótipos apresentaram rendimento acima da média geral, expressando melhor adaptação (VENCOVSKY e BARRIGA, 1992)

TABELA 1 - Resumo da análise de variância conjunta de experimentos conduzidos em dez ambientes, em que foram avaliados 14 genótipos de feijão do grupo carioca, quanto a produtividade de grãos. Epagri, Santa Catarina, anos agrícolas 2000/01 e 2001/02

\begin{tabular}{lcc}
\hline \multicolumn{1}{c}{ FV } & GL & QM $^{\mathbf{1}}$ \\
\hline Blocos/Ambiente & 30 & 219299,49 \\
Genótipos (Gen) & 13 & $529216,655^{* *}$ \\
Ambientes (Amb) & 9 & $42068123,45^{* *}$ \\
Gen x Amb & 117 & $235455,83^{* *}$ \\
Resíduo & 390 & 93307,67 \\
\hline Total & 559 & -- \\
\hline Média $\left(\mathrm{kg} \mathrm{ha}^{-1}\right.$ ) & 1906,00 & \\
CV (\%) & 16,03 & \\
\hline${ }^{* *}$ significativo a 1\% de probabilidade pelo teste F.
\end{tabular}

Com base nos parâmetros estimados pela metodologia de EBERHART e RUSSELL (1966) (Tabela 2), identificou-se os genótipos Vi 0699, Vi 4599, SCS Guará, LP 97-58 de adaptabilidade geral. Estes apresentaram coeficiente de regressão igual a unidade e alta previsibilidade, ou seja, desvio da regressão não significativo. SCS Guará e LP 97-58 também apresentaram coeficiente de regressão igual a unidade e desvio da regressão não significativo, entretanto a produtividade foi inferior a média geral. Porém, SCS Guará foi indicado para cultivo em Santa Catarina devido a sua estabilidade e adaptabilidade (ELIAS et al., 2005). Entretanto, o conjunto de 
ELIAS, H.T. et al. Estabilidade e adaptabilidade de linhagens...

genótipos e de ambientes estudados por estes autores foi distinto do avaliado no presente trabalho, além disto, a metodologia de estuda da estabilidade e adaptabilidade também foi distinta.

TABELA 2 - Parâmetros de estabilidade e adaptabilidade estimados segundo a metodologia de EBERHART e RUSSEL (1966), para a produtividade de 14 genótipos de feijão do grupo carioca, cultivados em dez ambientes. Epagri, Santa Catarina, anos agrícolas 2000/01 e 2001/02

\begin{tabular}{|c|c|c|c|c|}
\hline \multirow[b]{2}{*}{ Genótipos } & \multicolumn{4}{|c|}{ Parâmetros } \\
\hline & Médias & $\hat{?}_{1 i}{ }^{1}$ & QMDi/100 $\stackrel{2}{2}$ & $\mathrm{R}^{2}(\%)$ \\
\hline Vi 4899 & 2125,25 & $1,177^{\star *}$ & 61,328 & 98,71 \\
\hline LH 11 & 2008,31 & 0,959 & $226,107^{*}$ & 93,22 \\
\hline Vi 0699 & 2002,33 & 0,935 & 177,801 & 94,32 \\
\hline Vi 4599 & 2002,24 & 0,965 & 76,645 & 97,62 \\
\hline FT 97-155 & 1941,00 & $1,158^{* *}$ & 129,668 & 97,22 \\
\hline FTS Magnífico & 1934,81 & $1,183^{\text {** }}$ & $402,546^{\star *}$ & 92,16 \\
\hline Cl 9633 & 1932,35 & 1,007 & $235,697^{*}$ & 93,56 \\
\hline LP 96-153 & 1905,69 & 1,082 & $209,202^{*}$ & 94,98 \\
\hline SCS Guará & 1878,25 & 1,027 & 114,540 & 96,89 \\
\hline LP 97-28 & 1858,97 & 0,839 ** & 101,542 & 95,89 \\
\hline Carioca & 1831,70 & $0,807^{* *}$ & $396,123^{\star *}$ & 84,76 \\
\hline LP $97-58$ & 1806,18 & 1,011 & 103,239 & 97,10 \\
\hline Pérola & 1801,38 & 1,048 & $407,204^{\star *}$ & 90,12 \\
\hline TPS Bonito & 1655,49 & $0,805^{\star *}$ & 96,985 & 95,76 \\
\hline
\end{tabular}

1 ** significativo a $1 \%$ de probabilidade pelo teste $t$

$\underline{2} * * \mathrm{e}^{*}$ significativos a 1 e $5 \%$ de probabilidade pelo teste $\mathrm{F}$, respectivamente.

As linhagens LH 11, Cl 9633 e LP 96-153 também apresentaram boa performance, considerando todos os ambientes, e apesar do desvio da regressão destes ser significativo, os $\mathrm{R}^{2}$ (coeficientes de determinação) superam o nível de $80 \%$, considerado crítico por CRUZ e REGAZZI (1997) (Tabela 2). Assim, entre os genótipos de adaptabilidade geral, destacam-se quanto a peformance, especialmente as linhagens $\mathrm{Vi} 0699, \mathrm{Vi}$ 4599 e LH 11 com produtividades médias acima de $2000 \mathrm{~kg} \mathrm{ha}^{-1}$ e boa previsibilidade.

Com base nos índices ambientais, os ensaios conduzidos no ano agrícola 2000/01 nos municípios de Canoinhas, Campos Novos e Chapecó (segunda época), além do ensaio do ano 2001/02 em Chapecó, foram classificados como ambientes favoráveis.

As linhagens Vi 4899 e FT 97-155 apresentam adaptabilidade específica para ambientes favoráveis, altas médias de produtividade associada a alta previsibilidade. A cultivar FTS Magnífico não deve ser descartada, pois apresenta coeficiente de regressão maior que um, e apesar do desvio da regressão ser significativo, o $R^{2}(92,16 \%)$ é alto, o que segundo CRUZ e REGAZZI (1997) viabiliza sua recomendação (Tabela 2 ). Estes genótipos se destacaram também quanto a produtividade em ambientes favoráveis, com médias acima de $3000 \mathrm{~kg} \mathrm{ha}^{-1}$ (Tabela 3).

TABELA 3 - Parâmetros de estabilidade e adaptabilidade estimados pelo método proposto por CRUZ et al. (1989) para a produtividade de grãos $\left(\mathrm{kg} \mathrm{ha}^{-1}\right)$ de 14 genótipos de feijão do grupo carioca, cultivados em dez ambientes. Epagri, Santa Catarina, anos agrícolas 2000/01 e 2001/02

\begin{tabular}{|c|c|c|c|c|c|c|}
\hline \multirow[b]{2}{*}{ Genótipos } & \multicolumn{2}{|c|}{ Média em ambiente: } & \multirow[b]{2}{*}{$\hat{?}_{1 i}^{\prime}{ }^{1}$} & \multirow[b]{2}{*}{$\hat{?}_{1 i}^{\prime} ? \hat{?}_{2 i}^{\prime}{ }^{1}$} & \multirow[b]{2}{*}{ QMD $i \stackrel{2,3}{3}$} & \multirow[b]{2}{*}{$\mathrm{R}^{2}(\%)$} \\
\hline & Favorável & Desfavorável & & & & \\
\hline Vi 4899 & 3244,23 & 1379,27 & $1,162^{* *}$ & 1,419 & 56,54 & 98,96 \\
\hline FTS Magnífico & 3066,74 & 1180,19 & $1,174^{\star \star}$ & 1,345 & $454,05^{\star *}$ & 92,26 \\
\hline FT 97-155 & 3051,73 & 1200,52 & $1,155^{\star}$ & 1,205 & $147,69^{* *}$ & 97,23 \\
\hline LH 11 & 2939,24 & 1387,68 & 0,990 & $0,439^{*}$ & $196,19^{*}$ & 94,85 \\
\hline LP 96-153 & 2932,07 & 1221,44 & 1,072 & 1,246 & $232,87^{*}$ & 95,11 \\
\hline Vi 4599 & 2908,78 & 1397,88 & 0,961 & 1,024 & 86,77 & 97,64 \\
\hline SCS Guará & 2896,39 & 1199,48 & 1,055 & 0,562 & 81,16 & 98,07 \\
\hline Cl 9633 & 2887,10 & 1295,84 & 1,001 & 1,093 & $267,65^{\star *}$ & 93,61 \\
\hline Vi 0699 & 2860,62 & 1430,13 & 0,903 & 1,475 & 136,22 & 96,19 \\
\hline Pérola & 2842,46 & 1107,32 & 1,061 & 0,837 & $455,09^{* *}$ & 90,34 \\
\hline LP 97-58 & 2790,80 & 1149,76 & 1,008 & 1,057 & 117,50 & 97,11 \\
\hline LP 97-28 & 2669,28 & 1318,76 & $0,848^{*}$ & 0,656 & 108,52 & 96,16 \\
\hline Carioca & 2563,59 & 1343,78 & $0,786^{\star *}$ & 1,160 & 424,17 & 85,72 \\
\hline TPS Bonito & 2447,47 & 1127,50 & $0,824^{* *}$ & $0,483^{*}$ & 86,96 & 96,67 \\
\hline Média & 2864,32 & 1267,11 & - & - & - & - \\
\hline
\end{tabular}


Com adaptabilidade especifica a ambientes desfavoráveis foram identificados LP 9728, Carioca e TPS Bonito. Estes cultivares apresentaram coeficientes de regressão menor que a unidade e a exceção da cultivar Carioca, desvio da regressão não significativo, associados a elevados valores de $\mathrm{R}^{2}$ (Tabela 2). Entretanto, a média geral de TPS Bonito $\left(1655,49 \mathrm{~kg} \mathrm{ha}^{-1}\right)$ é baixa, bem como sua média em ambientes desfavoráveis $(1127,5 \mathrm{~kg}$ ha $\left.^{-1}\right)$.

O genótipo ideal para ambientes favoráveis, preconizado por CRUZ e REGAZZI (1997), não foi encontrado, pois nenhum $\hat{?}_{1 i}^{\prime} ? \hat{?}_{2 i}^{\prime}$ maior que a unidade foi significativo pelo teste $t(5 \%)$. Entretanto, destacam-se os genótipos de adaptabilidade geral, Vi 4899, Vi 0699 e Vi 4599, que apresentam boa performance tanto em ambientes específicos (Tabela 3), como na média dos ambientes (Tabela 2), estes genótipos apresentam também alta previsibilidade. A linhagem FT 97-155 e a cultivar FTS Magnífico apresentam alta produtividade e não devem ser julgadas totalmente indesejáveis para recomendação geral, pois o $\mathrm{R}^{2}$ está acima de $90 \%$, mostrando que não são imprevisíveis (Tabela 3). Para ambientes desfavoráveis, Carioca e LP 97-58 são os mais adaptados, apresentando baixa resposta as condições adversas do ambiente e alta previsibilidade e produtividade pouca acima da média destes ambientes (Tabela 3 ).

Com base no índice de recomendação proposto por ANNICCHIARICO (1992) (Tabela 4), as linhagens Vi 4899, Vi 0699, Vi 4599 e LH 11 se destacam pela boa performance nos ambientes em geral. Em condições especificas de ambientes favoráveis, especialmente Vi 4899 e FT 97-155, além de outro grupo que envolve FTS Magnífico, Vi 4599, LH 11, LP 96-153 e SCS Guará, apresentaram as melhores performances. Para ambientes desfavoráveis, as linhagens Vi 0699, Vi 4899, Vi 4599 e LH 11 apresentaram os maiores índices de recomendação.

TABELA 4 - Índice de recomendação estimado pelo método proposto por ANNICCHIARICO (1992) para produtividade de grãos de 14 genótipos de feijão do grupo carioca, cultivados em dez ambientes. Epagri, Santa Catarina, anos agrícolas 2000/01 e 2001/02

\begin{tabular}{lccc}
\hline & & Índice de recomendação \\
\cline { 2 - 4 } Genótipo & Ambiente geral & Ambientes favoráveis & Ambientes desfavoráveis \\
\hline Vi 4899 & 108,96 & 111,38 & 107,36 \\
Vi 0699 & 104,37 & 96,80 & 110,26 \\
Vi 4599 & 103,62 & 100,78 & 106,25 \\
LH 11 & 103,01 & 100,05 & 104,81 \\
Cl 9633 & 98,71 & 97,03 & 99,60 \\
LP 97-28 & 97,26 & 91,41 & 101,75 \\
FT 97-155 & 95,76 & 104,92 & 90,54 \\
SCS Guará & 95,37 & 99,45 & 92,84 \\
LP 96-153 & 94,63 & 99,92 & 91,31 \\
FTS Magnífico & 94,63 & 101,42 & 91,07 \\
Carioca & 93,95 & 85,39 & 100,23 \\
LP 97-58 & 91,30 & 95,88 & 88,49 \\
Pérola & 88,86 & 94,87 & 84,86 \\
TPS Bonito & 85,73 & 83,88 & 86,90 \\
\hline
\end{tabular}

Estes genótipos recomendados para ambientes desfavoráveis foram exatamente os mesmos que apresentaram as melhores performances para ambientes em geral, isto ocorreu, pois nametoobbgia pioposta porANNICCHIARICO (1992) a adaptabilidade de um genótipo é medida pela superioridade deste em relação à média de cada ambiente e, para obtenção do índice recomendação, que é simultaneamente uma medida de estabilidade e adaptabilidade, as médias relativas dos genótipos são ponderadas pelos seus respectivos desviospadrão no conjunto de ambientes considerado, mas de forma geral, os índices de recomendação são fortemente associados às médias. Observa-se que os quatro genótipos com maior índice de recomendação para ambiente geral (Tabela 4), são exatamente os de maior média geral (Tabela 2), o mesmo ocorre em ambientes desfavoráveis (Tabelas 4 e 3). Para ambientes favoráveis, os três maiores índices de recomendação (Tabela 4) são também dos genótipos de maior média nestes ambientes (Tabela 3).

Houve concordância entre as três metodologias na identificação de Vi 0699 e Vi 4599, e de duas metodologias na indicação de Vi 4899 e LH 11 como genótipos com adaptabilidade geral. As linhagens Vi 0699 e Vi 4599 foram identificadas em trabalho realizado em Minas Gerais, como adaptadas a ambientes gerais e desfavoráveis, respectivamente (OLIVEIRA et al., 2006). Em ambientes favoráveis, Vi 4899, FT 97-155 e FTS Magnífico foram simultaneamente indicados pelas metodologias de EBERHART e RUSSELL (1966) e ANNICCHIARICO (1992). Os genótipos LP 97-28 e Carioca foram identificados como de adaptabilidade específica a ambientes desfavoráveis, por duas metodologias, enquanto pelo índice de recomendação, Vi 0699, Vi 4899, Vi 4599 e LH 11 são os de melhor performance nestes ambientes. Sendo Vi 4599 também recomendado para este tipo 
de ambiente no Estado de Minas Gerais (OLIVEIRA et al., 2006).

De forma geral observou-se forte concordância entre as metodologias utilizadas, a exceção da recomendação para ambientes desfavoráveis baseada na metodologia não paramétrica. Destaca-se que, na utilização de metodologias não paramétricas tem-se a vantagem de sempre identificar, no grupo avaliado, aqueles de melhor performance para cada ambiente, visto que não há parâmetros ideais pré-estabelecidos.

Entre os genótipos avaliados, destaca-se a performance superior das linhagens em relação as cultivares. Esta superioridade prevaleceu tanto em termos de produtividade como de estabilidade, mostrando a viabilidade da utilização destas em programas de melhoramento e, de acordo com seu comportamento em relação às demais características de importância agronômica, podese avaliar a possibilidade torná-las cultivares comerciais.

\section{CONCLUSÕES}

1) As três metodologias foram concordantes identificando as linhagens Vi 0699 e Vi 4599 como de adaptabilidade geral, e a linhagem Vi 4899 foi identificada por duas metodologias;

2) Os genótipos Vi 4899 e FT 97-155, seguidos de FTS Magnífico foram os genótipos de melhor performance em ambientes favoráveis;

3) Os genótipos Carioca e LP 97-28 foram identificados pelas metodologias baseadas em regressão, e Vi 0699, Vi 4899 e Vi 4599 foram identificadas pelo modelo não paramétrico como os mais desejáveis em ambientes desfavoráveis;

4) Em algumas situações não há concordância entre as metodologias na indicação de genótipos, justificando o uso de duas metodologias não concorrentes simultaneamente.

\section{REFERÊNCIAS}

1. ANNICCHIARICO, P. Cultivar adaptation and recomendation from alfafa trails in Northern Italy. Journal of Genetics and Plant Breeding, v. 46, n. 3, p. 269-278, 1992.

2. CARBONELL, S.A.M., AZEVEDO FILHO, J.A.; DIAS, L.A.S.; GARCIA, A.A.F.; MORAIS, L.K. Common bean cultivars and lines interactions with environments. Scientia Agricola, v. 61, n. 2, p. 169-177, 2004.

3. COIMBRA, J.L.M.; CARVALHO, F.I.F.; HEMP., S.; SILVA, S.A. Adaptabilidade e estabilidade fenotipica em genótipos de feijão de cor (Phaseolus vulgaris) em três ambientes distintos. Ciência Rural, v. 29, n. 3, p. 441-448, 1999.

4. CRUZ, C.D. Programa Genes: versão Windows - Aplicativo computacional em genética e estatística. Viçosa: UFV, 2001. $648 \mathrm{p}$.

5. CRUZ, C.D.; CARNEIRO, P.C.S. Modelos biométricos aplicados ao melhoramento genético. v. 2. Viçosa: UFV, 2003. $585 \mathrm{p}$.

6. CRUZ, C.D.; REGAZZI, A.J. Modelos biométricos aplicados ao melhoramento genético. 2.ed.Viçosa: UFV, 1997. 390 p.

7. CRUZ, C.D.; TORRES, R.A.A.; VENCOVSKI, R. An alternative approach to the stability analysis proposed by Silva and Barreto. Revista Brasileira de Genética, v. 12, n. 3, p. 567-580, 1989.

8. EBERHART, S.A.; RUSSELL, W.A. Stability parameters for comparing varieties. Crop Science, v. 6, n. 1, p. 36-40, 1966.

9. ELIAS, H.T.; HEMP, S.; CANTON, T. Análise da interação genótipo x ambiente na avaliação de cultivares de feijão em Santa Catarina. Pesquisa Agropecuária Gaúcha, v. 5, n. 2, p. 271-275, 1999.

10. ELIAS, H.T; HEMP, S.; SCAPIM, C.A.; RODOVALHO, M.A.; ROYER, M.R.; MORA, F.; BARRETO, R.R. Análise de estabilidade e adaptabilidade de genótipos de feijoeiro no Estado de Santa Catarina. Acta Scientiarum, v. 27, n. 4, p. 623$628,2005$.

11. LIN, C.S. et al. Stability analysis. Where do we stand? Crop Science, v. 26, n. 5, p. 894-899, 1986.

12. NUNES, G.H.S.; ELIAS, H.T.; HEMP, S.; SOUZA, M.A. Estabilidade de cultivares de feijão-comum no Estado de Santa Catarina. Revista Ceres, v. 46, n. 268, p. 625-633, 1999.

13. OLIVEIRA, G.V.; CARNEIRO, P.C.S.; CARNEIRO, J.E.S.; CRUZ, C.D. Adaptabilidade e estabilidade de linhagens de feijão comum em Minas Gerais. Pesquisa Agropecuária Brasileira, v. 41, n. 2, p. 257-265, 2006.

14. PIMENTEL-GOMES, F. Curso de estatística experimental. 14 ed. Piracicaba: Degaspari, 2000. 477 p.

15. RAMALHO, M.A.P.; SANTOS, J.B.; ZIMMERMANN, M.J.O. Genética quantitativa em plantas autógamas; aplicações ao melhoramento do feijoeiro. Goiânia: Editora UFG, 1993. 271 p.

16. SCAPIM, C.A.; OLIVEIRA, V.R.; BRACCINI, A.L.; CRUZ, C.D.; ANDRADE, C.A.B.; VIDIGAL, M.C.G. Yield stability in maize (Zea mays) and correlations among the parameters of the Eberhart and Russell, Lin and Binns and Huehn models. Genetics and Molecular Biology, v. 23, n. 2, p. 387-393, 2000.

17. SILVA, C.A.F. Feijão. In: Síntese anual da agricultura de Santa Catarina 2005-2006. Florianópolis: Epagri/Cepa, 2006. p. 56-66.

18. THOMÉ, V.M.R.; ZAMPIERI, S.L.; BRAGA, H.J.; MASSIGNAM, A.M.; ALTHOFF, D.A.; PANDOLFO, C.; MIRANDA, G.X. Zoneamento agrícola para a cultura do feijão em Santa Catarina. Florianópolis: Epagri, 1997. 33 p.

19. VENCOVSKY, R.; BARRIGA, P. Genética biométrica no fitomelhoramento. Ribeirão Preto: Sociedade Brasileira de Genética, 1992. 486p. 